\title{
Hepatolenticular Degeneration
}

National Cancer Institute

\section{Source}

National Cancer Institute. Hepatolenticular Degeneration. NCI Thesaurus. Code C84756.

A rare autosomal recessive inherited disorder caused by mutations in the ATP7B gene. It

is characterized by copper accumulation in the tissues, particularly brain and liver. It results in liver failure, neurologic, and psychotic manifestations. 